\title{
A SUPERCONDUCTING SHORT PERIOD UNDULATOR
}

\author{
A. Geisler, A. Hobl, M. Schillo, ACCEL Instruments, Germany \\ R. Rossmanith, Forschungszentrum Karlsruhe, Germany
}

\begin{abstract}
Superconducting in-vacuo undulators reach higher fields at lower periods compared to permanent magnet undulators. After the first successful tests of such an undulator with beam in Mainz [1] and an analysis of the emitted radiation a team consisting of members of ACCEL and the Research Center Karlsruhe began to build a superconducting undulator for the $2.5 \mathrm{GeV}$ storage ring ANKA. In this paper (due to the limited space) a few aspects of the whole design are described.
\end{abstract}

\section{INTRODUCTION}

Conventional undulators are made either from permanent magnets or electromagnets. For shorter period lengths (FELs and X-ray undulators [5]) permanent magnets are the preferred ones. The wavelength of the emitted radiation is given by

$$
\lambda_{\text {Phot }}=\frac{\lambda_{u}}{2 n \gamma^{2}}\left(1+\frac{K^{2}}{2}\right)
$$

where $\mathrm{K}=0.94 \mathrm{~B}[\mathrm{~T}] \lambda_{\mathrm{u}}[\mathrm{cm}]$.

For $\mathrm{SmCo}_{5}$ permanent magnet undulators for instance the gap-width $\mathrm{w}$, the period $\lambda_{\mathrm{u}}$ and the maximum field $\mathrm{B}$ are related to each other by the formula [2]

$$
\mathrm{B}[\mathrm{T}]=1.55 \exp \left[-\pi \mathrm{w} / \lambda_{\mathrm{u}}\right]
$$

In order to exceed this field limit the Research Center Karlsruhe developed a first test device of a superconductive in-vacuo undulator. The test device undulator worked well with the Mainz microtron beam [1] and it was possible to demonstrate that such an undulator can be used with a gap as small as $2 \mathrm{~mm}$.

Nevertheless, the measurement at Mainz also indicated that improvements are necessary.

a.) The analysis of the emitted X-ray spectrum showed that the field at the entrance and the end of the undulator is insufficiently matched to the electron trajectory. This leads to the broadening of the spectrum.

b.) Field and phase errors in the test device were relatively high due to the fact that the accuracy of the positioning of the superconductive wires during coiling was insufficient. c.) In addition the measurement of the field in a superconductive undulator with Hall probes needs improvements: the Hall-probe has to be moved with an accuracy of several $10 \mu \mathrm{m}$ through the undulator in a vacuum and LHe environment.

d.) The cryostat of the test device was good enough for a $50 \mu \mathrm{A}$ beam from a microtron. In a storage ring the cryostat has to be built in such a way that a $200 \mathrm{~mA}$ beam does not deposite RF power. This power can cause quenches.

Therefore, as a next step Karlsruhe and ACCEL began to develop a prototype in order to overcome the above mentioned shortcomings of the test device. Since a.) to c.) can be tested without beam it was decided to divide the construction and the tests into two parts:

-The construction of a short test device (mock-up) in order to finalise the mechanical layout, the layout of the matching sections, the required external correction elements and the measuring technique and afterwards

-the construction of a full length undulator with a cryostat suitable for a storage ring

The parameter list for both is shown in Table I.

Table I

\begin{tabular}{|l|c|}
\hline Period length [mm] & 14 \\
\hline Number of periods of the final undulator & 100 \\
\hline Number of periods of the mock-up & 8 \\
\hline Nominal gap-width [mm] & 5 \\
\hline K at nominal gap-width & 2 \\
\hline
\end{tabular}

\section{LAYOUT OF THE UNDULATOR}

Fig. 1 shows the body of the short undulator. Liquid Helium flows through the central holes in the undulator body. The superconductive wires are fixed in grooves. Not shown in the 3-dimensional drawing are the spacers defining the gap and the fixations of the wires. The new helical coiling technique [3] compared to other superconducting undulator developments [4] is already described in previous papers.

A cross-section through one of the undulator coils is shown in fig. 2. The wires are pressed to the smooth inner curve. The variable curvature is designed in such a way 
that the superconductive wire can follow the curvature despite the stiffness of the wire.

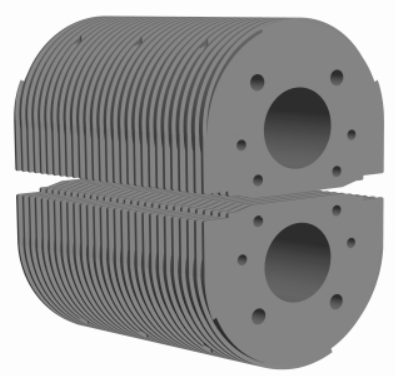

Fig. 1 The metallic body of the short undulator

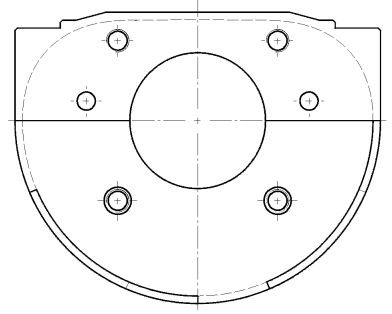

Fig. 2 Cross-section through the undulator.

\section{FIELD AND FIELD MATCHING OF A SUPERCONDUCTIVE UNDULATOR}

Fig. 3 shows the coiling arrangement. Each square in the grooves represents a superconductive wire with an approximate dimension of $1 \mathrm{~mm} \times 1 \mathrm{~mm}$. The different colours of the wires mark different directions of the current. In the grooves towards the centre of the undulator are 16 wires (right end side of fig. 3 ).

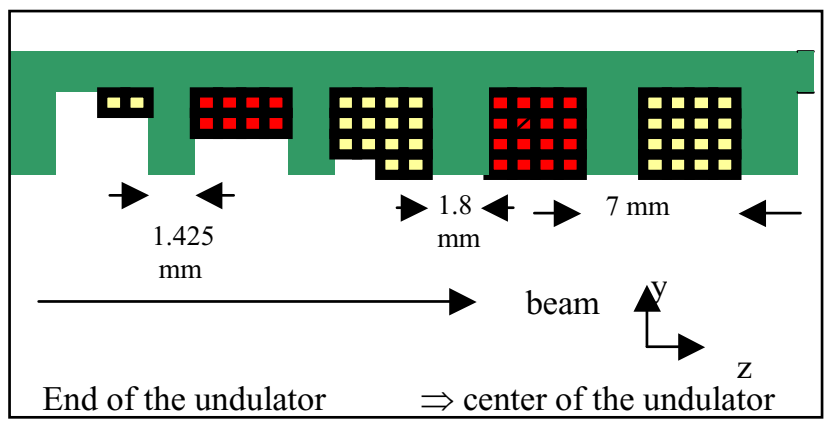

Fig. 3 The superconductive wire in the grooves. In order to obtain a period length of $14 \mathrm{~mm}$ and a k-value close to 2 each groove is filled with 16 wires. Towards the entrance of the undulator the number of the wires is reduced in order to match the particle trajectory.
Fig. 4 shows the technical realisation of fig. 3 (90 degree rotation between the 2 pictures). In order to demonstrate the quality of the coiling the iron (green part in fig. 3) is partly etched away.

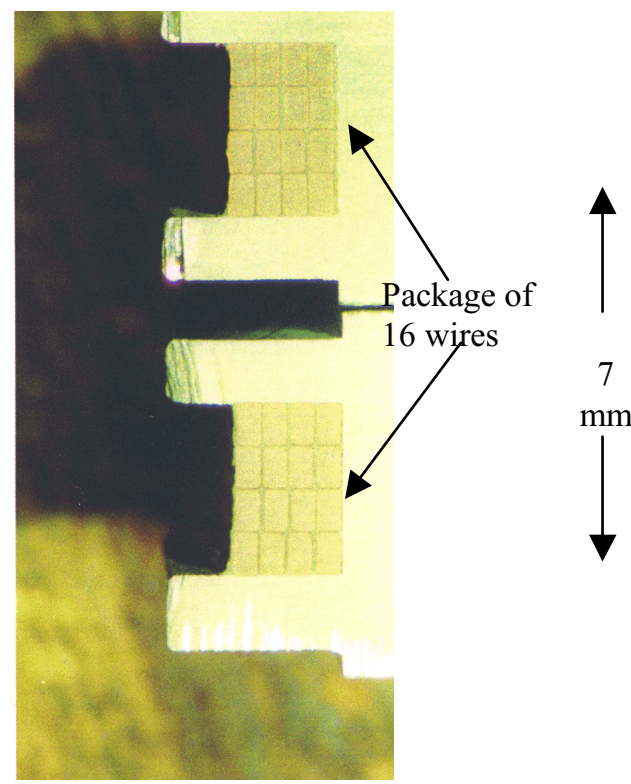

Fig. 4 Microscopic picture of the coiling. The iron (green part in fig. 3) is partly etched away in order to make the coiling better visible.

The calculated field for an idealised undulator is shown in fig. 5, the calculated first field integral in fig. 6 . In both cases it was assumed that the current density is 1000 $\mathrm{A} / \mathrm{mm}^{2}$.

Comparing fig. 3 and 5 makes it clear that the first and the last 3 grooves act as matching sections, the 12 grooves in between (or more) are identical (with alternating current direction).

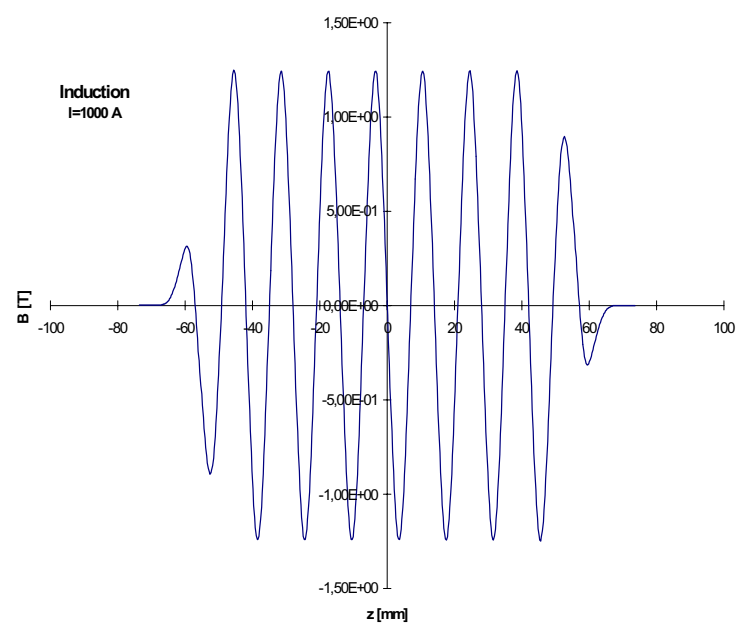

Fig. 5 Calculated field at a current density of 1000 $\mathrm{A} / \mathrm{mm}^{2}$ 


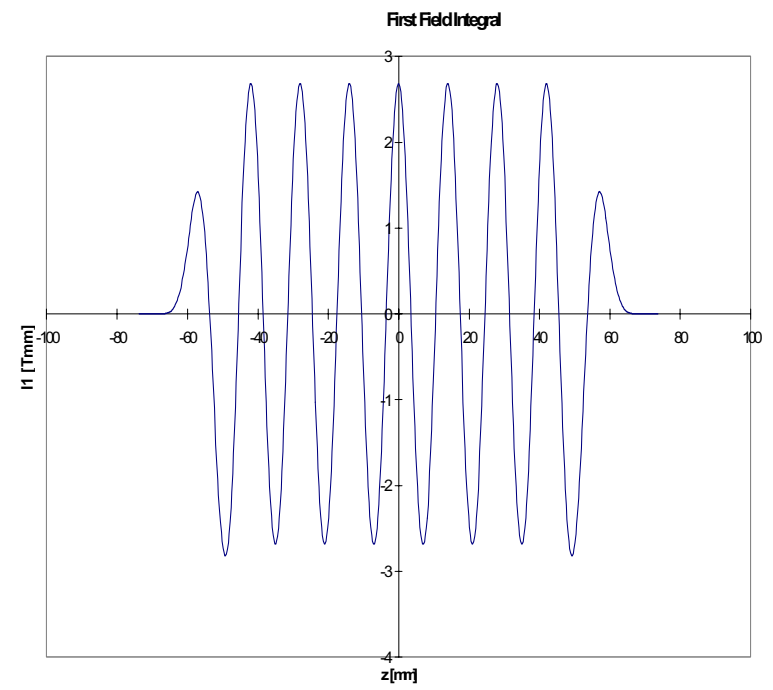

Fig. 6 Calculated first field integral [T.mm] at a current density of $1000 \mathrm{~A} / \mathrm{mm}^{2}$

\section{FIELD ERRORS DUE TO MECHANICAL ERRORS}

The cutting of the grooves into the body of the undulator and the positioning of the wires can only be performed with a limited accuracy. In order to estimate the influence of mechanical errors on the quality of the field and to specify acceptable tolerances the influence of the different potential mechanical errors are evaluated. The error budget is summarised in table II (see also coordinate system defined in fig. 3).

Table II: Error budget

\begin{tabular}{|l|l|l|}
\hline $\begin{array}{l}\text { Type of } \\
\text { error }\end{array}$ & $\begin{array}{l}\text { Description of } \\
\text { error }\end{array}$ & $\begin{array}{l}\text { Change of peak } \\
\text { field in Tesla for } \\
\text { an error of } 1 \mu \mathrm{m}\end{array}$ \\
\hline A & $\begin{array}{l}\text { pole height (y- } \\
\text { direction) }\end{array}$ & $1.10^{-4}$ \\
\hline B & $\begin{array}{l}\text { pole width (z- } \\
\text { direction) }\end{array}$ & $0.8 .10^{-4}$ \\
\hline C & $\begin{array}{l}\text { depth of the groove } \\
\text { (y-direction) }\end{array}$ & $1.10^{-4}$ \\
\hline D & $\begin{array}{l}\text { position of the groove } \\
\text { (z-direction) }\end{array}$ & $3.10^{-4}$ \\
\hline E & $\begin{array}{l}\text { longitudinal position } \\
\text { of the wire (z- } \\
\text { direction) }\end{array}$ & $2.2 .10^{-4}$ \\
\hline F & $\begin{array}{l}\text { vertical position of } \\
\text { the wire (y-direction) }\end{array}$ & $0.9 .10^{-4}$ \\
\hline
\end{tabular}

In Table II it is assumed that the errors are concentrated in the central groove. The dominating errors are $\mathrm{D}$ and $\mathrm{E}$.
Fig.7 shows the phase error for 100 different undulators with randomly distributed mechanical errors (A to F) of $\pm 10 \mu \mathrm{m}$ maximum (left co-ordinate) and the dipole component of the resulting field (right coordinate). The average phase errors is about 4 degrees. Dipole content and phase error are related so that an additional low current coil over the whole undulator can reduce strong phase errors. In addition the first and the last groove will be equipped with a correction coil. Summarising: three additional small power supplies will allow to optimise the particle trajectory.

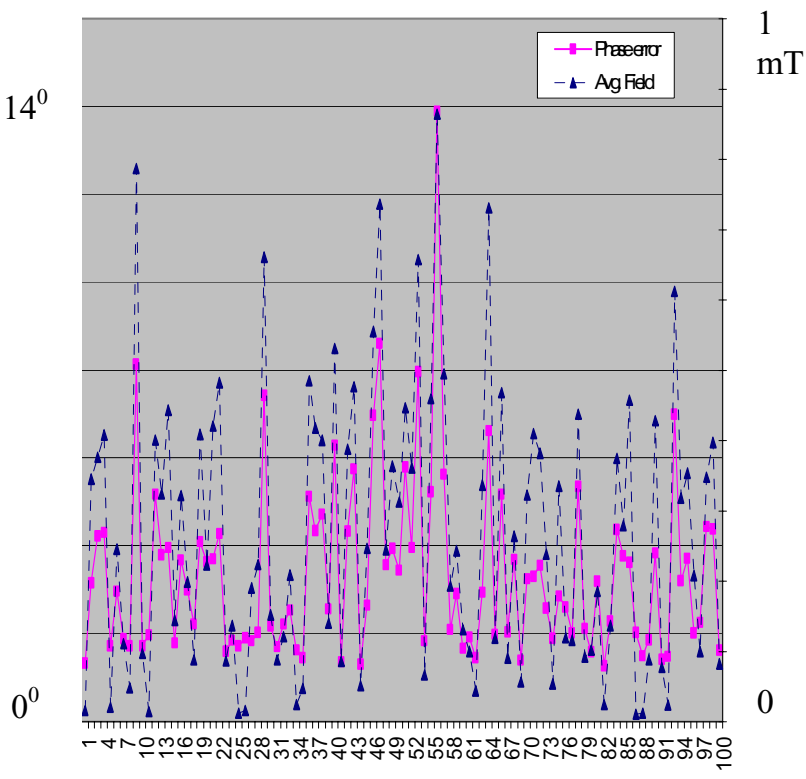

undulator number

Fig. 7 Correlation between phase errors in degrees (left co-ordinate and solid line) and the remaining dipole component (right co-ordinate and dotted line) for 100 undulators with randomly distributed errors $\mathrm{A}$ to $\mathrm{F}$.

\section{REFERENCES}

[1] T. Hezel et al., Experimental Results with a novel superconductive in-vacuum mini-undulator test device at the Mainz Microtron MAMI, Proc. PAC99, New York

[2] J. Murphy, Synchrotron Light Source Data Book, Internal Report BNL 42333J

[3] T. Hezel et al., A superconductive undulator with a period length of 3.8mm, J. Synchrotron Rad (1998) 5, 448

[4] I. Ben-Zvi et al., The Performance of a superconducting micro-undulator prototype, Nucl. Instr. and Meth. A297, 301

[5] G. Dattoli et al., Extreme Ultraviolet (EUV) Sources for Lithography based on Synchrotron Radiation, Nucl. Instr. Methods A, in press and Proc. of this conference 